\title{
The effect of blast-furnace slag particle size on the hydration of slag-Portland cement grouts at elevated temperatures
}

\section{Rebecca A. Sanderson}

Immobilisation Science Laboratory, Department of Materials Science and Engineering, The University of Sheffield, Sheffield, UK

\section{Gavin M. Cann}

National Nuclear Laboratory, Workington Laboratory, Workington, UK
John L. Provis

Immobilisation Science Laboratory, Department of Materials Science and Engineering, The University of Sheffield, Sheffield, UK (corresponding author: j.provis@sheffield.ac.uk) (Orcid:0000-0003-3372-8922)

The UK nuclear industry has historically used a unique specification of cement powder that differs from construction industry requirements. However, the slags that complied with this specification have become unavailable. The material now used to meet the requirements of the specification is a blend of standard construction industry ground granulated blast-furnace slag (GGBS), which has high fineness, with Calumite which is a coarser slag powder. Both materials have very similar chemical compositions, and the main reason for blending is to control the particle size distribution (PSD) to replicate the performance of the previous supply. The effect of changing the PSD on the performance properties of the cement paste was investigated. Isothermal conduction calorimetry at elevated temperatures was carried out to monitor the heat of hydration; it was found that the peak heat and total heat evolution increased with an increase in GGBS content. It was also found that Calumite contributes very little to the hydration reaction and thus behaves similarly to an inert filler. As the GGBS content was decreased, the fluidity of the pastes increased up to a certain point, but decreased again for systems dominated by very coarse particles, indicating that there is an optimum balance between the finer and coarser slag particles within this cementing system.

\section{Introduction}

Supplementary cementitious materials such as blast-furnace slag (BFS) and pulverised-fuel ash have been used as a partial replacement for Portland cement (PC) in UK and international nuclear waste encapsulation for many years (Angus et al., 2010; Sharp et al., 2003). Encapsulation in a cementitious wasteform is the current preferred method of disposal of intermediate level waste in the UK (Sharp et al., 2003).

The cement powders used for encapsulation in the UK must conform to tight specification requirements, both as a dry material and when combined in a grout. The series of baseline tests used by Sellafield Ltd (SL) to monitor grout performance is collectively known as an 'acceptance test' and includes assessments of fluidity, initial and final set, and heat of hydration and monitoring for any bleed or segregation of water. The current formulation used in the baseline tests is a 3:1 BFS/PC powder ratio with a 0.35 water/solids (w/s) mass ratio (Angus et al., 2010; Cann and Carruthers, 2012). The design and operating parameters at each of the various SL cementitious encapsulation plants are different and therefore small changes in their operational envelopes are observed, ranging from BFS/PC powder ratios of $9: 1$ to $7: 3$ and w/s ratios of $0 \cdot 31$ to $0 \cdot 37$. There are many advantages to having such a high degree of PC replacement in the grout, such as a reduced amount of heat generation, improvements in workability and increased long-term durability of the wasteform produced (Rashad and Sadek, 2017; Raut et al., 2015; Ulubeyli and Artir, 2015).
The SL site has historically used a unique cement powder specification, which has become unavailable due to structural and supply-chain changes in the UK cement and iron industries. Therefore, the nuclear industry has had to change its powder supply to a commercially available material used in the construction industry.

It is logical to expect that changes in the supply of BFS may alter the performance and chemical properties of cementitious grouts in the fresh and hardened states. In the nuclear industry, understanding the effect of these changes on the performance properties of the grout is essential due to the safety-critical nature of the application in which it is being used. Changes to grout performance will potentially determine whether the wasteform produced is suitable for disposal. The grout must produce a wasteform that conforms to strict guidelines such as possessing high durability, sufficient mechanical strength and being free of liquids or voids (RWM, 2015).

The grout material now used by SL is formed from a blend of ground granulated blast-furnace slag (GGBS), which is much finer than the initially specified UK nuclear specification powder, and a coarser slag fraction called Calumite (Cann et al., 2011). These two materials have very similar chemical compositions (being sourced from the same blast furnace), and the reason for blending the two is that the finer GGBS has increased reactivity and causes loss of fluidity and increased water demand (Cann and McLuckie, 2010; Farris et al., 2004). The coarser Calumite fraction is essential to decrease the 
surface area of the BFS fraction in order to help control the fluidity and heat evolution of the cement grout used for the infill of the irregularly shaped solids found in nuclear waste streams. This new blend must conform to the tight specifications required by the nuclear industry in order to produce reliable and consistent wasteforms.

In the work reported in this paper, the effect of changing the particle size distribution (PSD) of cement powder on the properties of BFS:PC cement pastes was investigated. The heat of hydration and the effect of increased temperatures were explored through conduction calorimetry. In addition, the fluidity and workability of the grout, which are essential performance parameters for site application, were studied. The experimental work was conducted at elevated temperatures to replicate the conditions inside large wasteforms, which are likely to experience autogenous heating.

\section{Experimental details}

\section{Materials}

All of the precursor materials used were supplied by Hanson Cement. The GGBS was supplied from the company's Scunthorpe works and was sourced from the blast furnaces on that site. Calumite is produced by Calumite Ltd and is also obtained from crushing of a slag granulate from the Scunthorpe works. The PC powder used was a SL grade, supplied from Hanson's Ribblesdale works. X-ray fluorescence was used to analyse the composition of the cement powders; the main components of each are listed in Table 1. The PSDs of the GGBS and Calumite were measured via laser diffraction and are shown in Figure 1.

It is clear from Figure 1 that the two BFS fractions have very different distributions: all of the GGBS material is below $100 \mu \mathrm{m}$, but the majority of the Calumite particles are larger than $100 \mu \mathrm{m}$. Thus, blends of these two materials will create a bimodal distribution with very few particles between 100 and $200 \mu \mathrm{m}$, meaning that the BFS produced would be a gapgraded powder. Cement pastes produced from gap-graded powders often have a lower water requirement due to the inclusion of coarser particles (Zhang et al., 2011a). It has also

Table 1. Main oxide components of GGBS, Calumite and PC as measured by X-ray fluorescence (wt.\%)

$\begin{array}{lccc} & \text { GGBS } & \text { Calumite } & \text { PC } \\ \text { Sodium oxide }\left(\mathrm{Na}_{2} \mathrm{O}\right) & 0.35 & 0.5 & 0.58 \\ \text { Magnesium oxide }(\mathrm{MgO}) & 8.1 & 7.9 & 2.3 \\ \text { Aluminium oxide }\left(\mathrm{Al}_{2} \mathrm{O}_{3}\right) & 11.6 & 11.3 & 4.9 \\ \text { Silicon dioxide }\left(\mathrm{SiO}_{2}\right) & 36.3 & 38.3 & 20.1 \\ \text { Potassium oxide }\left(\mathrm{K}_{2} \mathrm{O}\right) & 0.64 & 0.78 & 0.77 \\ \text { Calcium oxide }(\mathrm{CaO}) & 39.0 & 38.9 & 63.4 \\ \text { Ferric oxide }\left(\mathrm{Fe}_{2} \mathrm{O}_{3}\right) & 0.4 & 0.3 & 2.5 \\ \text { Sulfur trioxide }\left(\mathrm{SO}_{3}\right) & 0.53 & 0.31 & 3.6\end{array}$

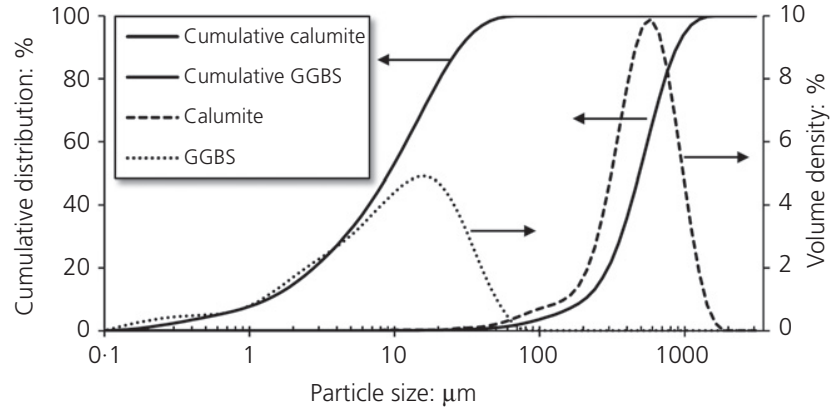

Figure 1. PSD data of GGBS and Calumite. A full-colour version of this figure can be found on the ICE Virtual Library

(www.icevirtuallibrary.com)

been shown that, compared with PC, the heat of hydration of a gap-graded cement has a slower release over the first $24 \mathrm{~h}$ but continues to increase rapidly, producing a different total heat evolution profile (Zhang et al., 2011b).

\section{Mix design}

The cement formulation used in this study was a blend of $3: 1$ BFS:PC by mass, at a $0.35 \mathrm{w} / \mathrm{s}$ ratio by mass. Additional w/s ratios $(0.33$ and $0 \cdot 37)$ were used to consider the effect of water content on the different grout formulations. Different BFS blends were prepared by varying the GGBS:Calumite ratios, as shown in Table 2.

\section{Methods}

\section{Isothermal conduction calorimetry (ICC)}

ICC was carried out to measure the heat output from the ten cementitious pastes (Table 2) at 25,35 and $60^{\circ} \mathrm{C}$. An eightchannel TAM Air calorimeter was used, with a $20 \mathrm{~g}$ sample of each formulation. The dry components were combined together in a sealed plastic container and blended before the addition of total water required. The paste was then externally mixed by hand for $2 \mathrm{~min}$. The homogeneous paste was then poured into small high-density polyethylene ampoules and loaded into the instrument.

Table 2. Blend ratios of GGBS:Calumite comprising the BFS fraction of each grout tested

\begin{tabular}{|lc|}
\hline Mix & GGBS:Calumite ratio: wt\% \\
\hline P100 & $100: 0$ \\
P80 & $80: 20$ \\
P72 & $72 \cdot 5: 27 \cdot 5$ \\
P65 & $65: 35$ \\
P58 & $58 \cdot 5: 41 \cdot 5$ \\
P52 & $52: 48$ \\
P42 & $42 \cdot 25: 57 \cdot 75$ \\
P32 & $32 \cdot 5: 67 \cdot 5$ \\
P22 & $22 \cdot 75: 77 \cdot 25$ \\
P0 & $0: 100$ \\
\hline
\end{tabular}




\section{ICC with quartz substitution}

Isothermal calorimetry was also carried out with quartz as a substitute for the Calumite fraction in each of the ten formulations (Table 2). The quartz was ground and sieved into fractions before blending the correct contributions from each PSD range to mimic the Calumite PSD.

\section{Slump test}

The workability of the cement pastes was measured by means of mini slump tests. The test apparatus was a scaled-down version of the standard Abrams slump cone widely used in the construction industry (Roussel et al., 2005). The mini cone was $57 \mathrm{~mm}$ high, with a $19 \mathrm{~mm}$ top and a $38 \mathrm{~mm}$ base. The test consists of filling an upturned cone with cement paste. The cone is then lifted vertically from a base plate and the cement paste is allowed to flow. The distance that the sample travels under gravity is measured by recording the area covered by the grout using a grid marked on the base plate. The flow areas reported here are the average of triplicate measurements for each sample.

\section{Results and discussion}

\section{Isothermal calorimetry analysis}

Isothermal calorimetry was carried out to determine the heat production rate of the samples and to obtain the total heat evolution of each cement paste. The ten formulations of different BFS fractions (Table 2) were analysed as 3:1 BFS:PC blends with a w/s ratio of $0 \cdot 35$. The samples were initially measured at $25^{\circ} \mathrm{C}$ as reported previously (Sanderson et al., 2017) and further testing was carried out at $35^{\circ} \mathrm{C}$ and $60^{\circ} \mathrm{C}$ to analyse the heat output of the cement pastes at elevated temperatures that may be more representative of the conditions inside a large waste container undergoing cementation. The full datasets are shown in Figure 2.

Similar heat evolution profiles were observed at 25, 35 and $60^{\circ} \mathrm{C}$. The results show that the peak heat and the total heat evolution both increased with an increase in GGBS content. This is to be expected due to the higher fineness of the GGBS compared with the Calumite causing greater reactivity in the P100 system compared with the coarser P0 mix. Previous investigations into the particle size of $\mathrm{BFS} / \mathrm{PC}$ systems also found that finer slags show a higher heat of hydration than coarser ones (Binici et al., 2007), consistent with the effect of the greater available reactive surface area.

\section{Comparison of isothermal calorimetry at 25,35 and $65^{\circ} \mathrm{C}$}

To determine the effect of temperature on these cement systems, a direct comparison of the extreme cases of the blends under investigation (i.e. P100 and P0) at all three temperatures is shown in Figure 3.

The results reveal a difference in heat output between the P100 and $\mathrm{P} 0$ cement pastes, which again is to be expected due to greater reactivity caused by increased fineness in the P100 sample (100\% GGBS) compared with P0 (100\% Calumite). The peak heat of P100 was approximately twice that of P0 equivalent. This finding was consistent across all three temperatures, suggesting that the main contributing factor is the PSD of the BFS blend and providing insight into the contribution of the GGBS component to the reaction of the blended cement. Numerous studies have shown that enhanced clinker hydration can be achieved by blending filler materials into cement systems and the particle size of the filler has a significant impact on the rate of reaction, commonly referred to as the 'filler effect' (Gutteridge and Dalziel, 1990; Lothenbach et al., 2011; Oey et al., 2013). The cement system considered here had a very high volume fraction of PC replacement by slag, and therefore the limited early-age reactivity of the BFS component of the blend (particularly the coarser Calumite particles) causes such an effect, allowing extra space for hydration of the clinker phase, and is conducive to enhanced nucleation.

Although the BFS fraction can contribute to the filler effect, it is common to overlook the reactivity of the filler itself (Lothenbach et al., 2011). Due to the chemical effect observed when reducing the GGBS content, a series of filler tests with the Calumite replaced by ground quartz of equivalent PSD was carried out to investigate what, if anything, Calumite actually contributes to the reaction process. The samples were analysed by isothermal calorimetry and the data collected show a very similar result to the original GGBS:Calumite blends, including the formation of peaks within the first $20 \mathrm{~h}$. Figure 4 shows the temperature profiles of the $\mathrm{P} 0$ grout and its quartz-substituted equivalent (Q0). Comparison of the results shows that the Calumite blend has a very similar heat of hydration to the 'inert' quartz. This replacement of Calumite with inert filler had very little impact on the cement hydration reaction, which confirms the minimal contribution of Calumite to the reaction process over the first $24 \mathrm{~h}$. It can therefore be assumed that the PC present in the system is responsible for the majority of the recorded heat output.

To obtain an indication of the reactivity of the GGBS (under the assumption that the Calumite contributes very little at this early stage) the data for P0 were subtracted from corresponding data for the P100 system (Adu-Amankwah et al., 2017; Kocaba et al., 2012; Whittaker et al., 2014). Figure 5 shows the resultant heat evolution profiles, which can be regarded as the contribution of the GGBS to the reaction process at each of the three experimental temperatures.

These results show that, in addition to the filler effect contribution and the increase in nucleation sites, the fine GGBS fraction also alters the rate of reaction. The GGBS contributed significantly to the heat of hydration at all three temperatures. There was also a shift in the time at which the peak heat evolution (i.e. the most rapid period of reaction) occurred between 
Advances in Cement Research

Volume 30 Issue 8
The effect of blast-furnace slag particle size on the hydration of slag-Portland cement grouts at elevated temperatures

Sanderson, Cann and Provis

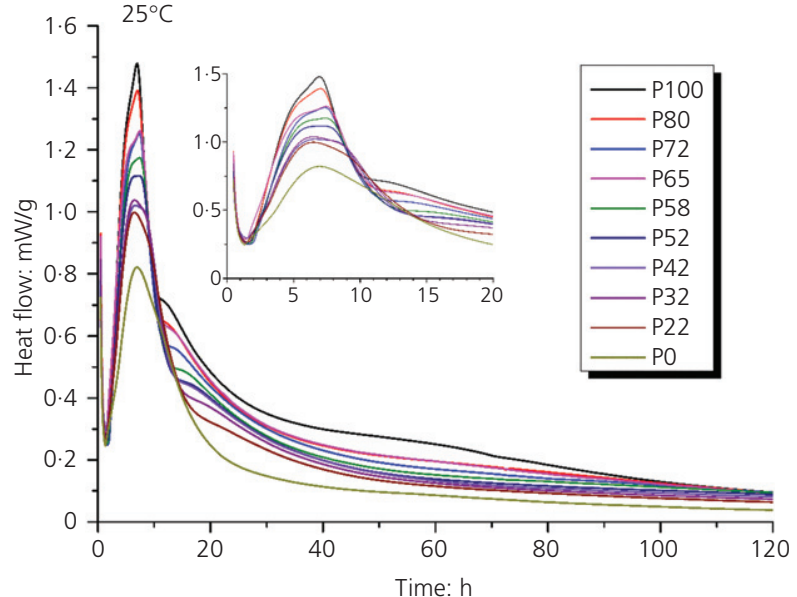

(a)

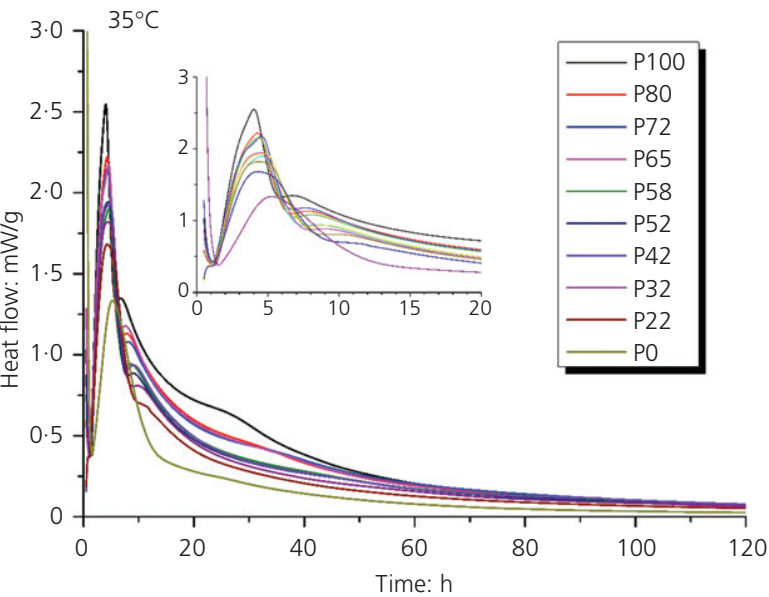

(c)

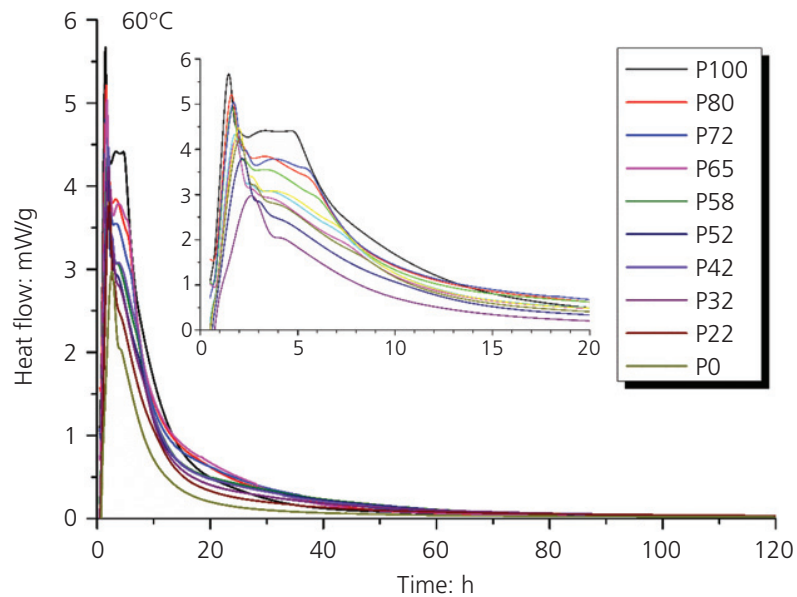

(e)

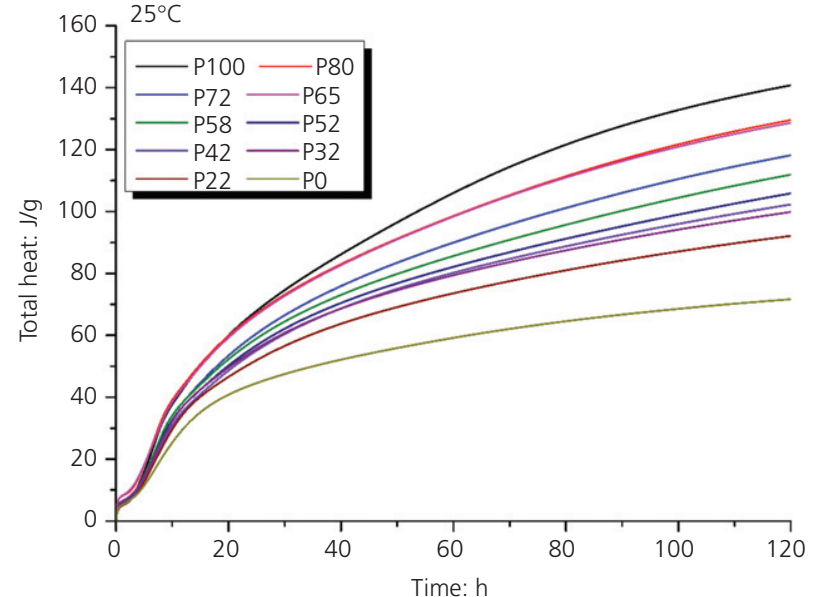

(b)

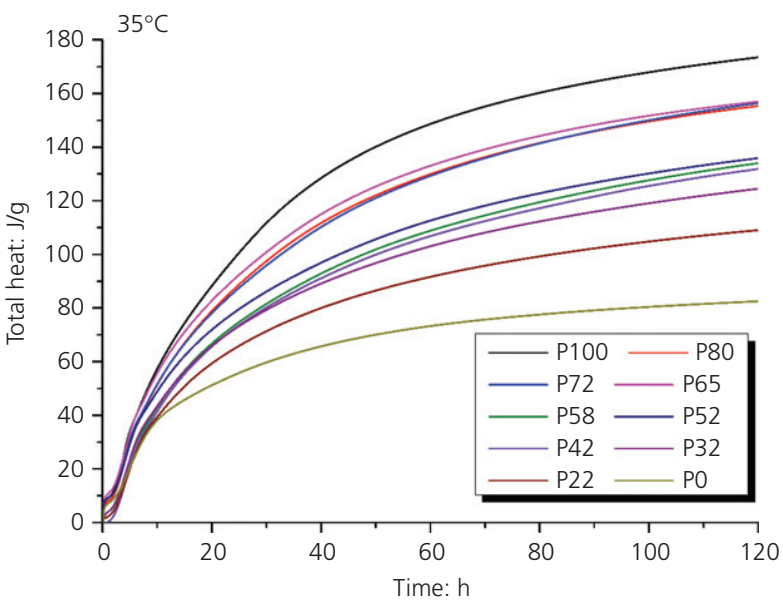

(d)

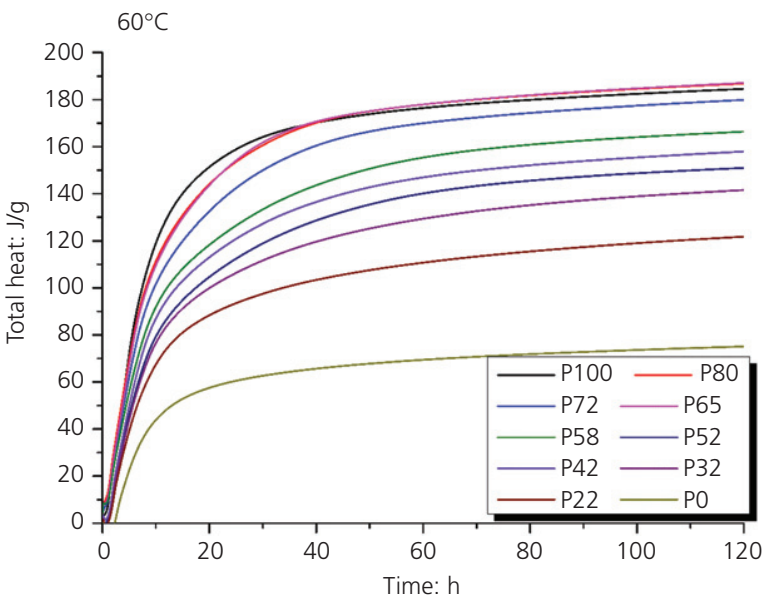

(f)

Figure 2. Isothermal calorimetry ((a), (c) and (e)) and total heat evolution ((b), (d) and (f)) curves measured at $25^{\circ} \mathrm{C}((\mathrm{a})$ and $(\mathrm{b})), 35^{\circ} \mathrm{C}$ $((\mathrm{c})$ and $(\mathrm{d}))$ and $60^{\circ} \mathrm{C}((\mathrm{e})$ and $(\mathrm{f}))$ for $120 \mathrm{~h}$ for the ten GGBS:Calumite blend ratios (Table 2$)$ at $\mathrm{w} / \mathrm{s}=0 \cdot 35$. A full-colour version of this figure can be found on the ICE Virtual Library (www.icevirtuallibrary.com) 


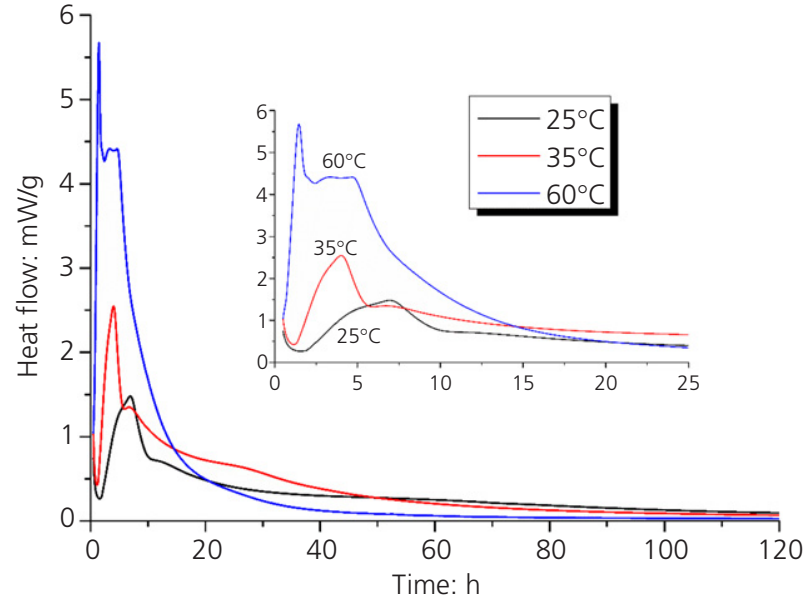

(a)

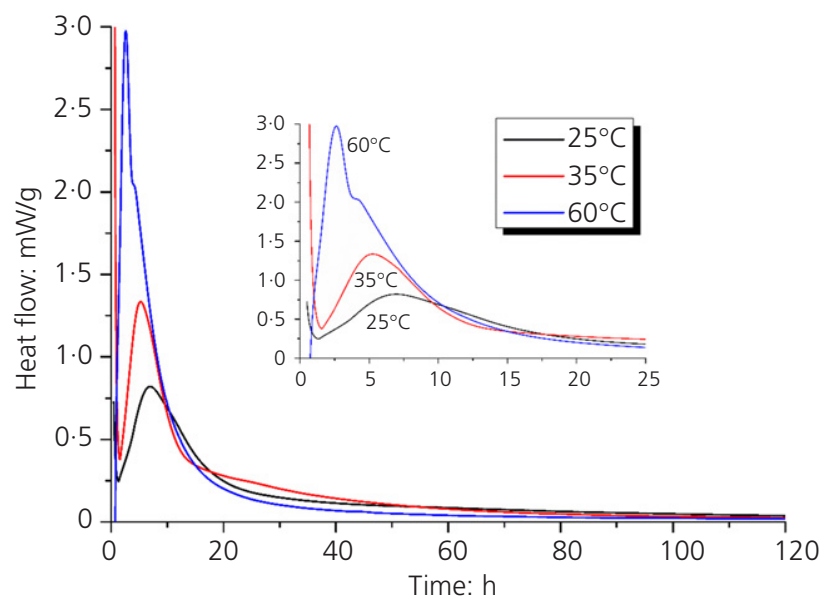

(b)

Figure 3. Isothermal calorimetry curves of mixes P100 (a) and PO (b) measured at 25,35 and $60^{\circ} \mathrm{C}$ for $120 \mathrm{~h}$ at w/s $=0 \cdot 35$. A full-colour version of this figure can be found on the ICE Virtual Library (www.icevirtuallibrary.com)

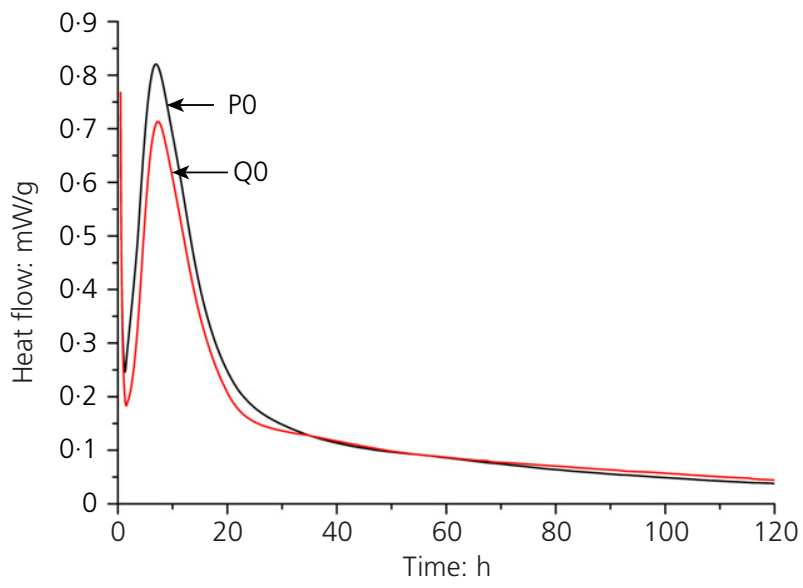

(a)

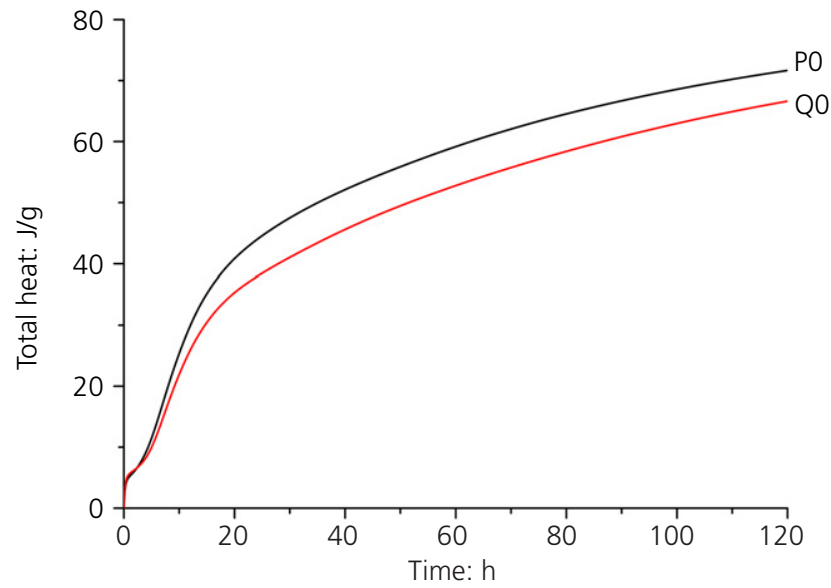

(b)

Figure 4. Isothermal calorimetric data for the PO and Q0 systems measured at $25^{\circ} \mathrm{C}$ for $120 \mathrm{~h}$ at w/s $=0 \cdot 35$ : (a) differential curves; (b) cumulative curves. A full-colour version of this figure can be found on the ICE Virtual Library (www.icevirtuallibrary.com)

the different experimental temperatures; this lengthened with decreasing temperature, confirming that an increase in temperature causes acceleration in setting. This finding agrees with previous studies that reported a similar pattern when different experimental temperatures were used during isothermal calorimetry (Klemczak and Batog, 2016; Wu et al., 1983).

The peak in heat evolution, attributed to the GGBS contribution, also changed in intensity between the P100 and P0 systems. It is thus also possible that there is a difference in the activation energies of GGBS and Calumite, meaning that increased temperature accelerates the reaction to different extents for each material. The hydration of Calumite was slower than that of the GGBS, and therefore requires more clinker to drive the reaction (Kolani et al., 2012). The overall activation energy of the P0 system was controlled by the PC, as the contribution of Calumite is minimal and it reacts only to a limited extent at early age, whereas the GGBS-containing system showed contributions from both BFS and PC components.

The total heat output from of the GGBS (P100) and Calumite (P0) systems for all three temperatures is shown in Figure 6. By comparison of $\mathrm{P} 100$ with $\mathrm{P} 0$, is it clear that the GGBS system generated a cumulative heat output approximately twice that of the Calumite mix during the first $120 \mathrm{~h}$. Again, this would be expected due to the increased reactivity caused by the higher surface area of the slag powder providing more nucleation sites for the hydration of clinker phases (Lothenbach et al., 2011). 


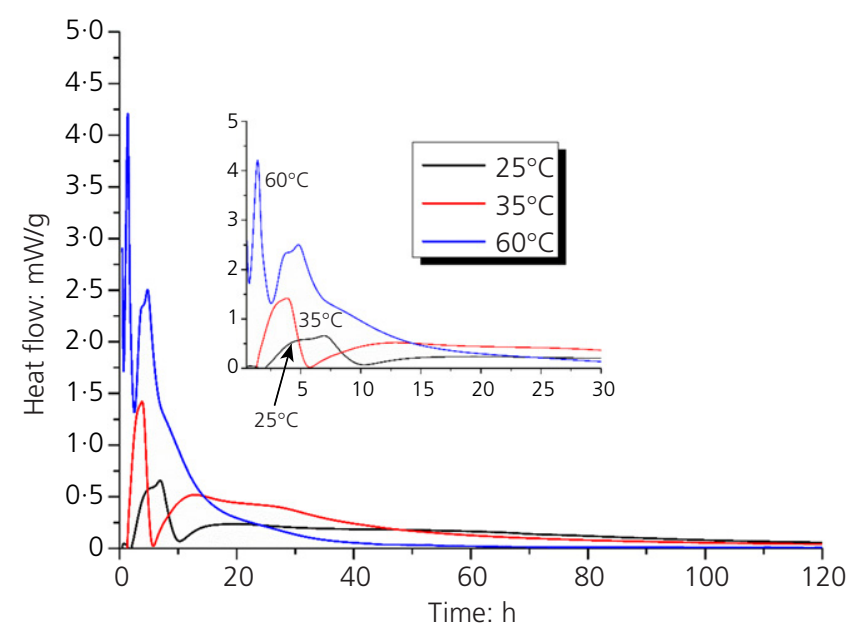

Figure 5. Isothermal calorimetry difference curves ( $\mathrm{PO}$ subtracted from P100) measured at 25,35 and $60^{\circ} \mathrm{C}$ for $120 \mathrm{~h}$ at w/s $=0.35$. A full-colour version of this figure can be found on the ICE Virtual Library (www.icevirtuallibrary.com)

For the $\mathrm{P} 0$ blend, the $35^{\circ} \mathrm{C}$ sample started to generate more heat than the $60^{\circ} \mathrm{C}$ sample at around $40 \mathrm{~h}$. The likely reason for this is the slow reaction rate of the Calumite. At the higher temperature of $60^{\circ} \mathrm{C}$, the $\mathrm{PC}$ reacts too quickly, not allowing enough time for portlandite generation to activate the Calumite before the material stiffens, particle surfaces are blocked by hydration products and mass transport is hindered, causing the Calumite reaction to be even slower than would otherwise be the case. Conversely, the temperature of $35^{\circ} \mathrm{C}$ provides better control for the Calumite:PC system, allowing increased energy for the reaction to occur but over a longer timescale, which in turn allows the Calumite to contribute to the reaction, causing a higher overall total heat output.

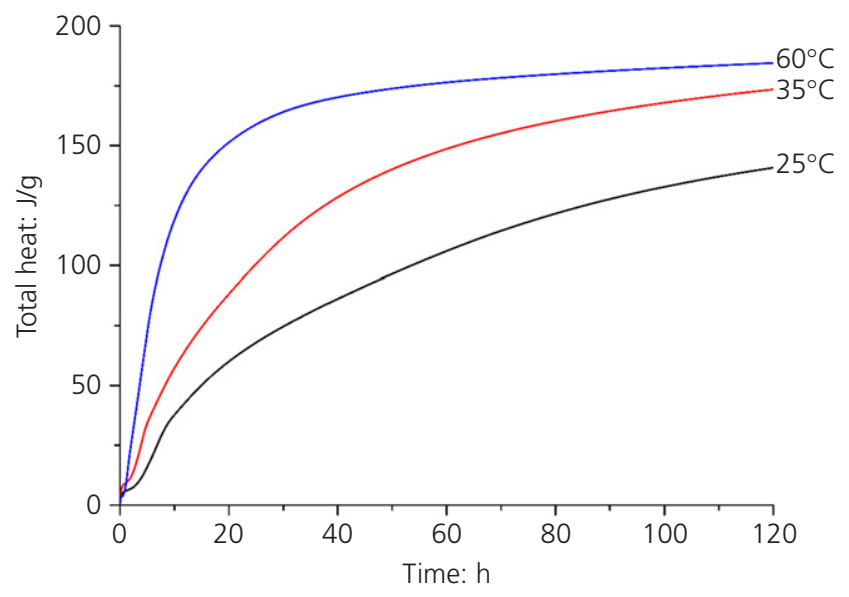

(a)
Within the SL specification, a low total heat evolution is one of the main criteria required when considering different grout formulations. The SL specification requires that the grout should not have a cumulative heat output greater than $180 \mathrm{~kJ} / \mathrm{kg}$ of blended cement powder after $24 \mathrm{~h}$ of hydration at $35^{\circ} \mathrm{C}$. All of the cement systems investigated in this work conformed to this specification and were even within the required maximum heat output when tested at $60^{\circ} \mathrm{C}$.

\section{Analysis of mini slump tests}

Other performance properties of the BFS:PC system are also important for the encapsulation of nuclear waste: the fluidity and workability of the cement grout used in encapsulation plant processes are particularly critical. Due to the nature of encapsulation plants, cement pastes need to have a sufficiently long working time and large enough flow to be processed without causing any issues in the production of wasteforms by remote handling operations. The mini slump test is a simple but useful method of measuring the workability of cement formulations and highlights the effect of water on the properties of the system at different blend ratios. Figure 7 shows the results of all ten blends at three different w/s ratios.

As expected, a higher w/s ratio led to a larger mini slump area for each blend. However, simply increasing the water content is not a suitable solution to improve flow characteristics because it can cause the formation of a layer of bleed water on the top of hardened cement paste and also has detrimental effects on physical properties such as strength and stability. In the context of nuclear waste disposal, bleed water would become an unwanted secondary waste that would need additional processing because free liquids are not permitted in wasteforms for disposal (RWM, 2015). Quantitative determination of bleed characteristics was not carried out in this study but,

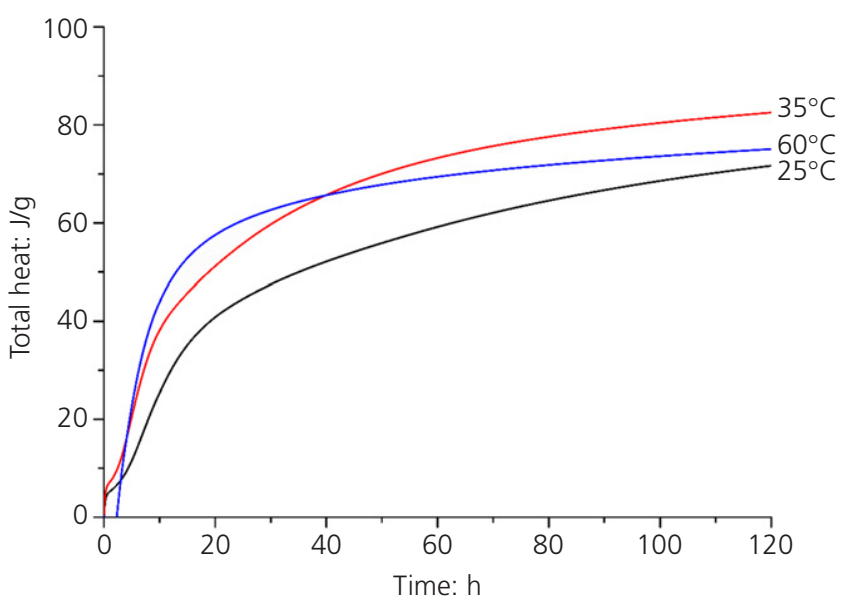

(b)

Figure 6. Cumulative heat evolution curves of mixes P100 (a) and P0 (b) measured at 25,35 and $60^{\circ} \mathrm{C}$ for $120 \mathrm{~h}$ at $\mathrm{w} / \mathrm{s}=0 \cdot 35$. A full-colour version of this figure can be found on the ICE Virtual Library (www.icevirtuallibrary.com) 


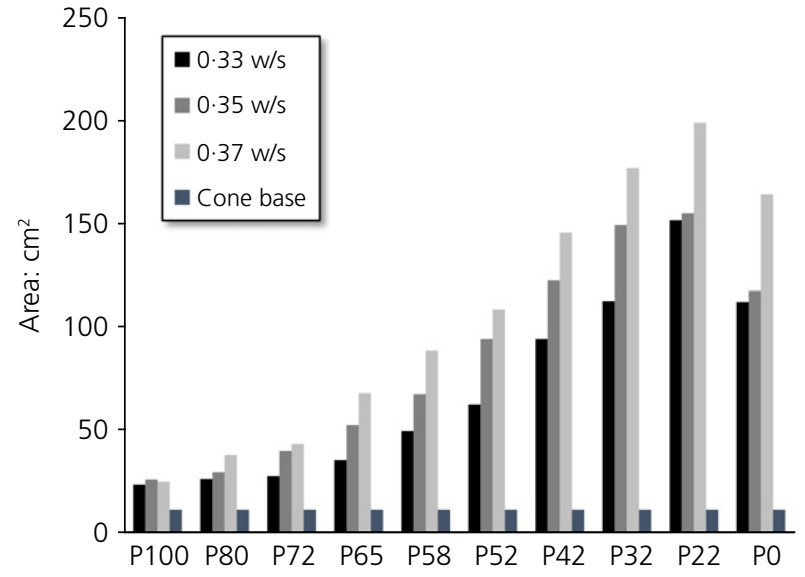

Figure 7. Mini slump areas for the ten GGBS:Calumite blend ratios at 3:1 BFS:PC ratio at $\mathrm{w} / \mathrm{s}$ ratios of $0.33,0.35$ and 0.37 with the cone base area shown for comparison

qualitatively, visible segregation or bleed was only observed at the extremes of the testing envelope (i.e. high Calumite and water contents).

An interesting observation from this series of experiments was that as the surface area of the material decreased the slump area increased, but only up to a point. Blends P32 and P22 evidently reached the point where the balance between large and small particles was no longer favourable for increasing fluidity. Another consideration is that gap-graded powders have a low water requirement (Zhang et al., 2011a, 2011b) and the results suggest that the bimodal PSD also reaches an optimum with regard to water content. This suggests that there needs to be an optimum contribution from both the GGBS and Calumite materials to enable good flow.

\section{Conclusions}

The results from this study showed that changing the PSD of the BFS fraction in blended cement systems containing both coarse and fine slag fractions significantly affects the heat output from the cement during hardening. The two extremes of the fine:coarse (GGBS:Calumite) blends were explored and were found to behave differently at elevated temperatures. All of the cements considered, even at elevated temperatures, conformed to the total heat evolution restriction of the UK specifications and could therefore potentially be used for encapsulation according to this criterion.

The mini slump tests showed that fluidity increased as the surface area of the slag decreased, but the results also highlighted the importance of a balanced blend. When there are too many larger particles, the filling of smaller grains in between them is not effective, which has a negative effect on the workability of the cement pastes. Blend P22 blend showed the highest workability across all three w/s ratios investigated.
The systems with the highest w/s ratio $(0 \cdot 37)$ achieved the largest slumps, but fluidity cannot be achieved in a practical sense by purely increasing water content due to bleed, settlement and the risk of increasing the corrosion of reactive metals.

\section{Acknowledgements}

The authors would like to acknowledge the Engineering and Physical Sciences Research Council (EP/G037426/1) and Sellafield Ltd for collective funding of this EngD project. R. A. Sanderson would also like to thank the Engineering Doctorate Centre at the University of Manchester and the National Nuclear Laboratory for their support and supervision. Thanks also go to Hanson Cement for supplying materials.

\section{REFERENCES}

Adu-Amankwah S, Zajac M, Stabler C, Lothenbach B and Black L (2017) Influence of limestone on the hydration of ternary slag cements. Cement and Concrete Research 100: 96-109.

Angus MJ, Godfrey IH, Hayes M and Foster S (2010) Managing change in the supply of cement powders for radioactive waste encapsulation - twenty years of operational experience. Proceedings of WM2010, Phoenix, AZ, USA. WM Symposia, Phoenix, AZ, USA, paper no. 10122.

Binici H, Temiz H and Köse MM (2007) The effect of fineness on the properties of the blended cements incorporating ground granulated blast furnace slag and ground basaltic pumice. Construction and Building Materials 21(5): 1122-1128.

Cann GM and Carruthers K (2012) MEP - Source of Product Quality Parameters. National Nuclear Laboratory, Workington, UK.

Cann GM and McLuckie BH (2010) Assessment of Alternative Blast Furnace Slag Supply from Scunthorpe Works. National Nuclear Laboratory, Workington, UK.

Cann GM, Carruthers K, McLuckie BH and Borwick J (2011) Scunthorpe GGBS/Calumite Blend Assessment for Use in ILW Encapsulation Processes. National Nuclear Laboratory, Workington, UK.

Farris S, Miller E, Wright E and Shepherd H (2004) Alternative BFS Suppliers. BNFL, Workington, UK.

Gutteridge WA and Dalziel JA (1990) Filler cement: the effect of the secondary component on the hydration of Portland cement. Cement and Concrete Research 20(6): 853-861.

Klemczak B and Batog M (2016) Heat of hydration of low-clinker cements. Journal of Thermal Analysis and Calorimetry 123(2): 1351-1360.

Kocaba V, Gallucci E and Scrivener KL (2012) Methods for determination of degree of reaction of slag in blended cement pastes. Cement and Concrete Research 42(3): 511-525.

Kolani B, Buffo-Lacarrière L, Sellier A et al. (2012) Hydration of slag-blended cements. Cement \& Concrete Composites 34(9): 1009-1018.

Lothenbach B, Scrivener K and Hooton RD (2011) Supplementary cementitious materials. Cement and Concrete Research 41(12): 1244-1256.

Oey T, Kumar A, Bullard JW, Neithalath N and Sant G (2013) The filler effect: the influence of filler content and surface area on cementitious reaction rates. Journal of the American Ceramic Society 96(6): 1978-1990.

Rashad AM and Sadek DM (2017) An investigation on Portland cement replaced by high-volume GGBS pastes modified with micro-sized metakaolin subjected to elevated temperatures. International Journal of Sustainable Built Environment 6(1): 91-101. 
Raut SR, Saklecha PP and Kedar RS (2015) Review on ground granulated blast-furnace slag as a supplementary cementitious material. Proceedings of International Conference on Quality Up-gradation in Engineering, Science and Technology. BDCE, Sevagram, Maharashtra, India, paper no. 8.

Roussel N, Stefani C and Leroy R (2005) From mini-cone test to Abrams cone test: measurement of cement-based materials yield stress using slump tests. Cement and Concrete Research 35(5): 817-822.

RWM (Radioactive Waste Management) (2015) Geological Disposal: Guidance on the Production of Encapsulated Wasteforms. RWM, Didcot, UK.

Sanderson R, Cann GM and Provis JL (2017) Comparison of calorimetric methods for the assessment of slag cement hydration. Advances in Applied Ceramics 116(4): 186-192.

Sharp JH, Hill J, Milestone NB and Miller EW (2003) Cementitious systems for encapsulation of intermediate level waste. Proceedings of the 9th International Conference on Radioactive Waste
Management and Environmental Remediation, Oxford, UK. ASME, New York, NY, USA, pp. 1425-1433.

Ulubeyli GC and Artir R (2015) Sustainability for blast furnace slag: use of some construction wastes. Procedia - Social and Behavioral Sciences 195: 2191-2198.

Whittaker M, Zajac M, Ben Haha M, Bullerjahn F and Black L (2014) The role of the alumina content of slag, plus the presence of additional sulfate on the hydration and microstructure of Portland cement-slag blends. Cement and Concrete Research 66: 91-101.

Wu X, Roy DM and Langton CA (1983) Early stage hydration of slag-cement. Cement and Concrete Research 13(2): 277-286.

Zhang T, Yu Q, Wei J and Zhang P (2011a) A new gap-graded particle size distribution and resulting consequences on properties of blended cement. Cement \& Concrete Composites 33(5): 543-550.

Zhang T, Yu Q, Wei J, Zhang P and Chen P (2011b) A gap-graded particle size distribution for blended cements: analytical approach and experimental validation. Powder Technology 214(2): $259-268$.

\section{How can you contribute?}

To discuss this paper, please submit up to 500 words to the editor at journals@ice.org.uk. Your contribution will be forwarded to the author(s) for a reply and, if considered appropriate by the editorial board, it will be published as a discussion in a future issue of the journal. 